\title{
Los tepehuanes y sus predecesores: un ensayo bibliográfico
}

Paul Liffman

\section{(2) OpenEdition}

\section{Journals}

Edición electrónica

URL: https://journals.openedition.org/jsa/11589

DOI: 10.4000/jsa. 11589

ISSN: 1957-7842

Editor

Société des américanistes

\section{Edición impresa}

Fecha de publicación: 5 diciembre 2010

Paginación: 267-288

ISSN: 0037-9174

\section{Referencia electrónica}

Paul Liffman, «Los tepehuanes y sus predecesores: un ensayo bibliográfico», Journal de la Société des américanistes [En línea], 96-2 | 2010, Publicado el 10 diciembre 2014, consultado el 02 septiembre 2022. URL: http://journals. openedition. org/jsa/11589 ; DOI: https://doi.org/10.4000/jsa. 11589 


\title{
LOS TEPEHUANES Y SUS PREDECESORES: UN ENSAYO BIBLIOGRÁFICO
}

\author{
Paul LIFFMAN *
}

\section{INTRODUCCIÓN}

El presente ensayo ${ }^{1}$ aborda varios debates claves sobre la arqueología, etnografía e historia - tanto social como lingüística - de la vasta y poco estudiada región tepehuana (o'dam) de Durango, México. Se toma como punto de partida la reciente publicación de La sierra tepehuana: asentamientos y movimientos de población (Cramaussel y Ortelli 2006), un volumen multidisciplinario de ensayos. Se enfoca en las formas de articulación entre grupos cuyas identidades distintas se cuestionan en el debate. El libro del cual surge esta reflexión consta de 18 capítulos: cuatro de arqueología ${ }^{2}$, diez de historia ${ }^{3}$ y cuatro de etnografía ${ }^{4}$. Complementa de cierta forma la colección Nómadas y sedentarios en el Norte de México: homenaje a Beatriz Braniff compilada por Marie Areti Hers y José Luis Mirafuente (2000). En vez de plantear una imagen falsa de consenso sobre la arqueología e historia de lo que Cramaussel y Ortelli bien describen como " el grupo más extendido geográficamente del septentrión novohispano », estos cápitulos ejemplifican algunos de los contrastes teóricos además de brindar información en forma sintética sobre el tema. Entonces el propósito del presente ensayo es explicitar algunos de los ejes centrales de debate, aclarar algunas de sus bases empíricas (sobre todo en el área lingüística) y, partiendo de esto, plantear los posibles puntos de enlace entre distintos puntos de vista.

El tema dominante del libro es el de las líneas de conexión, a través de supuestos linderos culturales y ecológicos, a lo largo del eje temporal y dos ejes espaciales. Las conexiones norte-sur entre la zona hohokam en el ahora suroeste de Estados Unidos y la parte medular y urbanizada de Mesoamérica a lo largo de la Sierra Madre Occidental se reconocen en varios momentos, pero lo que es más significativo para la mayoría de los autores son los vínculos entre el desierto

* Centro de Estudios Antropológicos, El Colegio de Michoacán, Martínez de Navarrete 505, 59699 Zamora, Michoacán, Mexico [pliffman@uchicago.edu].

Journal de la Société des Américanistes, 2010, 96-2 pp. 267-288. OS Société des Américanistes. 
oriental alto (habitado por zacatecos y pueblos oto-mangues), los valles serranos orientales, la misma sierra (caxcanes y tepehuanes), los valles occidentales (acaxees y xiximes) y la costa del Pacífico (cultura Aztatlán) ${ }^{5}$. Es decir, el cambio de enfoque desde el eje norte-sur (el llamado "corredor tepehuán ») hacia el este-oeste podría considerarse uno de argumentos teóricos más llamativos. Esto es particularmente clave para los tepehuanes, quienes aparentemente ocupaban tres de los cinco nichos que se acaban de mencionar - desierto, valles orientales y sierra ${ }^{6}$. William Merrill (communicación personal) coincide con este enfoque cuando sugiere que los tepehuanes se agrupaban a lo largo de las faldas orientales de la Sierra Madre Occidental para participar en el intercambio más de bienes estratégicos (como la sal) entre mar y desierto que de los bienes de lujo de norte a sur, aunque los dos tuvieran su importancia relativa. Una prueba de esta hipótesis sería si las poblaciones tepehuanas se concentraban más en torno a aquellas rutas este-oeste de este comercio. Luego, como todos los pueblos no tenían el mismo acceso a todas las regiones ecológicas, los que se encontraron más restringidos al desierto oriental habrían tenido que ser más móviles, por no decir « nómadas » y así diferenciarse culturalmente y relacionarse con otros grupos en su entorno, los cuales a su vez se contrastaron aun más con la matriz yuto-azteca.

Otra cuestión clave (que también cabe bajo el rubro de las relaciones norte-sur vs este-oeste) tiene que ver con el eje temporal: el grado de articulación entre la cultura tepehuana con la tradición anterior de los chalchihuiteños, y a la vez con las culturas oficialmente " mesoamericanas » hacia el sur. Una pregunta específica es si los tepehuanes fueran descendientes directos de los chalchihuiteños, presentes en la región desde hace al menos 1500 años, como planteó la tradición arqueológica de Estados Unidos. Otra hipótesis es que los tepehuanes fueran allegados norteños recientes del periodo post-clásico tardío que simplemente re-ocuparon sitios chalchihuiteños y se reapropiaron de aspectos de su cultura material (pp. 81, 84, 85). Este punto de vista se apoya en la historia lingüística, aunque ésta abarca teorías que manifiestan desacuerdos entre sí. En el siguiente apartado se discuten aspectos claves de estas teorías con respecto a la historia de los tepehuanes.

Un tercer tema principal del libro, que se aborda en el segundo apartado de este ensayo, es intrínseco a cualquier discusión de los tepehuanes: la resistencia, los mecanismos de alianza que posibilitaban tales respuestas al dominio colonial, y la fluidez de la organización indígena en general. En particular se refiere a la « brujería » (es decir, ciertas prácticas chamánicas o rituales) como lenguaje de poder, el multilingüismo y otras formas interculturales de los diversos grupos, indígenas e hispanos. 


\section{Prehistoria}

El arqueólogo Fernando Berrojalbiz resume la perspectiva generalmente compartida entre varios co-autores del volumen respecto a los ejes geográficos y temporales así:

Entre los años 600 y 1250, la primera migración provino del sur, del territorio zacatecano y era portadora de una cultura mesoamericana, la Cultura Chalchihuites. La segunda, la migración de los tepehuanes, salió de regiones situadas al norte, acarreó un modo de vida distinto que creó un paisaje diferente, dos o tres siglos antes de la Conquista. (p. 95)

Para abordar estas cuestiones en orden capitular, en el ensayo de la arqueóloga Marie-Areti Hers, «La sierra tepehuana: imágenes y discordancias sobre su pasado prehispánico », la cuestión central es la de las relaciones entre esferas culturales a través de los antemencionados ejes norte-sur y este-oeste. Hers pareciera tratar el cambio cultural como cuestión de migraciones más que como impacto de influencias sobre pueblos, los cuales no necesariamente se cambian de lugar a la par con tales cambios. Por ejemplo, respecto a los cambios asociados con el colapso chalchihuiteño $(1000 \mathrm{dC})$ Hers arguye que

eventos dramáticos [...] pusieron fin a la ocupación mesoamericana de gran parte del territorio zacatecano [...] los purépecha norteños [...] regresan a sus tierra michoacanas [...] y también [...] los tolteca-chichimeca que fundaron Tula junto con grupos locales. En ambos casos son grupos de inmigrantes de origen norteño que imponen, junto con su poderío militar, el tzompantli y la guerra florida, el chac mool [...] y el salón aporticado. (pp. 41-42) ${ }^{7}$

Aparte de identificar migraciones de pueblos como causa del cambio cultural, este capítulo es el primero del volumen que avanza la teoría que los tepehuanes llegaron en torno al siglo XIII (o aún más tarde), acontecimiento « que corresponde a la desaparición de los ocupantes mesoamericanos ». Esta posición encuentra eco en el capítulo siguiente, de Yoshiyuki Tsukada, " Grandes asentamientos chalchihuiteños en la Sierra Madre durangueña », entre otros. Los exponentes de dicha interpretación citan a menudo al lingüista histórico Leopoldo Valiñas cuando aseveran que la ahora geográficamente extensa subfamilia tepimana (tepehuan-tepecano y pima-pápago) apenas empezó a diferenciarse del tronco yuto-nahua entre los siglos XII y XVI (p. 89; véase Valiñas y Cortina Borja 1987).

Valiñas y Cortina Borja (1987, p. 387) plantearon el siglo xvi como posible fecha de separación de las lenguas tepehuanas. Esto pareciera contradecir la advertencia inicial que « este artículo no es glotocronológico; no hablamos de fechas ni de siglos mínimos de divergencia ». En todo caso «los tepimanos se 
hallaban, aparentemente, muy homogéneos y casi inmóviles, para luego empezar a moverse aceleradamente, unos hacia el norte y otros hacia el sur, lo que resulta difícil de explicar » $\mathrm{y}$ « [...] ya estando en el actual estado de Sonora [...] se dividan los tepehuanes, quienes van moviéndose rápidamente hacia el sur. Este movimiento divide a los tarahumaras de los guarijíos. [...] lograron penetrar en el actual estado de Durango » (ibid., pp. 405-407). Aunque se rechace una mapeación geográfica de las divergencias léxicas, se intenta proyectar modelos estadísticos multi-dimensionales de esta diferenciación en términos de movimientos concretos de poblaciones, un poco parecido al método de Hers. Se interpela el lugar histórico de origen yuto-azteca como el punto medio entre las ubicaciones geográficas de las variaciones lingüísticas conocidas en la historia reciente, ajustando la « distancia » (en doble sentido, estadístico y geográfico) según las desviaciones estándares que cada variación léxica dista de otra. Además, este intento de plantear una correlación entre variación lingüística y distribución espacial se ve afectada por otras variables, como el contacto cultural, que inciden en la « distancia léxica » por motivos no-geográficos. En el caso de los coras, se trata de hablantes « detenidos por otros grupos que poseen una cultura más compleja » (ibid., p. 406).

A la vez, Valiñas $(2000$, p. 202) señala que Wick Miller $(1983 ; 1984)$ dató la separación entre tepehuán del norte y sur hasta finales de la época colonial, es decir el siglo xvIII. Como resultado, la diferencia lingüística entre tepehuán del norte y tepecano, idiomas esparcidos a lo largo de más de 1500 kilómetros, no es mucho mayor que la que existe entre español y portugués. Sin embargo, la cercanía espacial hasta tiempos recientes no parece ser una explicación en sí suficiente de la coherencia entre lenguas, pues el índice de lexemas cognadas entre tepehuán del norte y del sur es de $82 \%$ a pesar de su gran separación geográfica, mientras que entre huichol y cora, lenguas vecinas y emparentadas que constituyen otra subfamilia yuto-nahua en sí, el índice es apenas de $58 \%$ (Valiñas 1994, pp. 137 cuadro 3, 157). Asimismo, según el lingüista Terrence Kaufman (communicación personal), la diferenciación fonológica dentro de la subfamilia tepimana es aparentemente mínima, lo cual también podría sugerir una fecha relativamente tardía de separación, y William Merrill postula una fecha en torno a 1150. Así, la separación sería contemporánea con el colapso tolteca.

Sin embargo, en una obra posterior a la de 1987 el mismo Valiñas no es tan tajante al respecto. Más bien señala que « la fuerte semejanza lingüística » entre los idiomas de la subfamilia tepimana puede explicarse de dos formas: « a) que la separación haya sido reciente, o b) que, aunque haya sido temprana, los diferentes grupos tepimanos se hayan mantenido en contacto. Como se ve, cualquiera de estas posibilidades es históricamente significativa »(Valiñas 2000, p. 201). Así, la primera hipótesis apoyaría la noción de una llegada repentina y tardía de tepehuanes hacia Durango poco antes de la invasión española, mientras que la segunda abre la posibilidad de contacto constante entre hablantes de lenguas 
tepimanas a pesar de una fecha temprana de separación física. En este último caso, la integración sostenida de la misma matriz cultural chalchihuiteña (por medio de intercambios políticos, económicos y culturales) explicaría el grado impresionante de coherencia lingüística a través de un espacio tan vasto ${ }^{8}$.

Al mismo tiempo Hers hace un comentario interesante sobre el icono del flautista (conocido como Kokopelli en Nuevo Mexico) que se encuentra representado en petrograbados a lo largo de toda la región chalchihuiteña, y sobre el conjunto más amplio de relaciones sobre vastos espacios territoriales:

nos evoca la aún vigente y vigorosa geografía sagrada huichola, población también dispersa en pequeños caseríos aislados en la sierra y muy probablemente heredera en gran medida, junto con los coras y los mexicaneros, de estos antiguos pobladores mesoamericanos [i.e. los chalchihuiteños]. (p. 40)

Por un lado el comentario interesa por la conexión que plantea entre tepehuanes y sus vecinos nayaritas, que evidentemente influyeron el idioma y la práctica ritual de los tepehuanes del sur en tiempos mucho más recientes que la separación inicial de lenguas yuto-aztecas (véase Reyes 2004 para una descripción extensa de los rasgos mesoamericanos de los tepehuanes sureños actuales). Sin embargo, se puede inferir que, al menos para Hers, una de las poblaciones actuales de la región - la nayarita - sí es descendiente directo de los mesoamericanos, mientras que otra que comparte características culturales centrales - la tepehuana - no lo es. Es decir, uno de los interlocutores implícitos en toda la discusión sobre los orígenes de los tepehuanes (pero en gran medida ausente de cualquier discusión en el libro) es Phil C. Weigand. Él sigue a Riley y Winters (1963) con el planteamiento que los tepehuanes son los descendientes de la tradición Loma San Gabriel-Chalchihuites implantada durante un milenio y medio. Tal vez cuando haya datos lingüísticos más precisos sobre las fechas probables de separación entre los diversos ramos de la subfamilia tepimana se puede aclarar el asunto, pues los datos arqueológicos aparentemente no lo comprueban para todos los interlocutores.

El aporte de José Luis Punzo Díaz, «Quiénes vivían en la sierra antes de la llegada de los tepehuanes? Breviario de arqueología xixime », aclara la cronología general de la región y el traslape de la transformación de la cultura chalchihuiteña, la cual era contemporánea con los anasazi, con las influencias desde Aztatlán en la costa occidental en torno al año 1000. De la misma manera plantea que después llegaron los invasores tepehuanes en torno a 1200, desde la sierra del norte. Una imagen recurrente del libro que expresa este autor es la del «papel protagónico que jugó la sierra como bastión de los grupos mesoamericanos en el septentrión de Mesoamérica » (p. 65). Al mismo tiempo otro de los puntos de tensión es precisamente entre, por un lado, los que como Hers aseveran, una presencia mesoamericana directa hasta la llegada de los tepehuanes, quienes a la vez se contrastaban con los grupos nómadas, y, por otro lado, los que plantean 
una mayor continuidad entre las poblaciones semi-mesoamericanizadas y los más rústicos de la región. No queda muy claro qué tanto estos últimos autores atribuirían a alguna tradición mesoamericana ingerencia directa en la región.

Con referencia al punto anterior, el capítulo de Fernando Berrojalbiz Cenigaonaindia, « Desentrañando un norte diferente », es importante porque resalta uno de los debates centrales del libro. Es decir, cuestiona si los tepehuanes tuvieran una cultura netamente mesoamericana en algún momento. Sin declararlo de forma directa, otra vez disputa implícitamente el argumento de Weigand (y explícitamente, los de sus antecesores intelectuales James Alden Mason, Carl Sauer, Donald Brand, Isabel Kelly, Carroll Riley y Charles Kelley) que «los tepehuanes del Contacto eran descendientes de una cultura autóctona, la Cultura Loma San Gabriel, fuertemente aculturada por otra mesoamericana, llamada Cultura Chalchihuites, que llegó a la región y desapareció posteriormente » (p. 68, véase 71 ff. 10, 88; Weigand y García 1996, p. 92). De hecho Berrojalbiz y Hers rechazan la existencia de la llamada cultura Loma San Gabriel como tal, interpretando este conjunto de datos arqueológicos como un aspecto chalchihuiteño periférico en vez de un pueblo distinto influenciado por los mesoamericanos.

En particular, Riley y Winters (1963, p. 184) habían adelantado múltiples motivos para apoyar la hipótesis que « los tepehuanes son descendientes de un grupo Loma [San Gabriel] chalchihuitizado que había vivido en el área de Durango oriental y central durante muchos siglos antes de Colón ». Se apoyaban en particular en las tradiciones de cerámica, arquitectura doméstica, malacates (pesas para hilar), pipas chamánicas, varas y plazas ceremoniales, y en la distribución histórica de la población. Sin embargo, admitían que una diferencia entre las dos culturas era la falta de centros ceremoniales y una clase especializada de sacerdotes entre los tepehuanes. Tal vez esta falta se debió a que la cultura Loma San Gabriel - catecoría cuya diferencia de Chalchihuites no queda tan clara según Berrojalbiz - fuera efectivamente el campesinado subordinado pero también aculturado de la cultura Chalchihuites y no contaba con una elite ceremonial propia o bien a los efectos de la invasión española. Dichos arqueólogos de los años 1960s también sugerían una conexión posible entre Loma San Gabriel y los zacatecos (ibid., p. 180). De manera paralela, el mismo Weigand plantea la hipótesis que « como sistema social compuesto, multi-étnico y multicultural, la cultura Chalchihuites es el mejor candidato para ser un importante elemento histórico (tanto cultural como físicamente) de los grupos que posteriormente serían conocidos como caxcanes ».

Los argumentos más fuertes contra este modelo de continuidad se basan en la antemencionada coherencia lingüística de los variantes tepimanos (sobre todo los tepehuanes) a lo largo de un espacio tan vasto. Además, toda la subfamilia incluye hasta en el extremo sur de su extensión geográfica características fonológicas, un mecanismo morfosintáctico y préstamos léxicos del idioma yumano ribereño (maricopa) y posiblemente del zuñi, familias lingüísticas no 
yuto-aztecas, en la región multilingüe hohokam del sur de Arizona (Shaul y Hill 1998 , pp. 381-382, 388, 392). Aparte, hay una relativamente mayor variación en las lenguas tepimanas del norte, lo cual, siguiendo leyes generales propuestas por Edward Sapir, apuntaría a dicha región como zona de origen (ibid., p. 386; véase Mandelbaum 1949) ${ }^{9}$. Estas características resultan difíciles de explicar sin una fecha tardía de separación y migración desde el norte. Es decir que los tepehuanes, aunque llegaran tarde a la región, como indica la evidencia lingüística, igualmente podían haberse aculturado a varios aspectos claves de la cultura chalchihuiteña, como hicieron posteriormente con la cultura nayarita más hacia el sur. Esto sería un reflejo de la profundidad de la interacción a lo largo del eje este-oeste de intercambio entre mar y desierto y, como señalan casi todos los estudiosos en el volumen de Cramaussel y Ortelli, la naturaleza multilingüe y multicultural de estas sociedades durante siglos.

Al mismo tiempo, Berrojalbiz sustenta su argumento sobre la sustitución radical de la población chalchihuiteña-gabrieleña por la tepehuana en parte en la observación que ésta ocupaba diferentes nichos ecológicos con un patrón de asentamiento menos nucleado relativo a sus predecesores de la tradición chalchihuiteña y que sembraban maíz en milpas altas de temporal en vez de sistemas de riego en el fondo del valle (p. 72). La cuestión sería si cambiantes condiciones ecológicas o políticas explicarian este cambio o si, de hecho, hay evidencia física para la desaparición de una población humana y la llegada de otra distinta. A diferencia de la brecha planteada en el eje temporal entre tepehuanes y los habitantes anteriores, en el eje espacial sincrónico, el punto de vista expuesto por Berrojalbiz sugiere una cultura compuesta que abarca los pueblos de desierto, sierra y planicie costera. Esta suerte de continuo recuerda el modelo de Leach (1964) de la alternancia entre formas de organización en los altos de Birmania.

Como señala el título del capítulo de Salvador Álvarez, « De "zacatecos" y "tepehuanes". Dos dilatados parcialidades de chichimecas norteñas », este autor; igual que Berrojalbiz, difiere de cualquier modelo de migración o ascendencia mesoamericana para explicar la cultura de los dos señalados grupos geográficamente extensos de la región bajo discusión al momento de contacto europeo. En cambio, enfatiza « procesos de continuidad e interacción cultural entre grupos caracterizadamente agricultores, habitantes de zonas montañosas y de otras zonas secas e inhóspitas [...] procesos a los que difícilmente se les podría atribuir como origen la presencia de "migrantes" mesoamericanos o de eventuales "pochtecas" " [comerciantes de larga distancia] (p. 128).

De hecho, sigue al conquistador Nuño de Guzmán al caracterizar a todos los habitantes de la región como chichimecas (p. 98) aunque seguramente ese militar del siglo XVI minimizó diferencias culturales y exageró el barbarismo de las poblaciones que encontró para justificar su propia violencia genocida. Se destaca el interés de Álvarez (y luego Cramaussel) en deconstruir la distinción caxcán/zacateco junto con otras categorías coloniales y sustituirlas por 
realidades sociales más fluidas ${ }^{10}$. En todo caso Álvarez adopta una postura clara en el debate sobre la relevancia de movimientos de poblaciones desde el centro de Mesoamérica hacia el norte para entender la cultura chalchihuites y si ésta chocó con poblaciones autóctonas no-mesoamericanas. Álvarez disputa cualquier distinción « bipolar » (p. 104) entre la relativamente alta civilización (de los pueblos caxcanes o chalchihuiteños) y los grupos de "paleo-indios » autóctonos que supuestamente nunca adoptaron la agricultura de maíz (aunque de alguna manera la transmitieron hasta el actual suroeste de Estados Unidos). Cabría mencionar que, a pesar del contraste entre esta perspectiva y otra que atribuyera una influencia directa de Mesoamérica en la región (la cual estaba encontrada con otras poblaciones), todos - incluyendo a Weigand, el interlocutor implícitamente más polarizado de Álvarez - aparentemente comparten la noción de una convivencia jerarquizada entre chalchihuiteños y san gabrieleños o caxcanes y zacatecos. Quizás este « continuum » dentro de la misma tradición mesoamericana se organizaba en torno a un sistema tributario centrado en Teul, a pesar de las posibles diferencias lingüísticas y eventuales conflictos violentos (Weigand y García 1996, pp. 106, 112). Más bien, pareciera que la cuestión gira en torno al grado de diferenciación entre estos grupos, no en si estaban interrelacionados o no. Pues en este continuo teórico Álvarez quisiera caracterizar dicha diferenciación como mucho más matizado que otros autores.

Así este autor ve las reificaciones contenidas dentro de las fuentes coloniales, las cuales erigen distinciones étnicas o territoriales marcadas entre poblaciones indígenas, como artefactos del colonialismo europeo. Al menos en un sentido tiene razón porque la lucha anti-colonial sigue vigente hasta nuestros tiempos en la Sierra Madre Occidental, ya que estos pueblos reivindican una territorialidad sumamente extensa, traslapada y variable (según la temporada y propósito específico), tal como Hers la resumió arriba. En vez de posesión exclusiva y permanente, se trata de una territorialidad fluida en agricultura rotativa, caceríarecolección y comercio ritualizado.

En contraste con las representaciones « bipolares », Álvarez señala las continuidades entre seis poblaciones:

1) los habitantes de la planicie costera del Pacífico;

2) los acaxees y xiximes de los valles occidentales de la Sierra Madre;

3) estos últimos con los tepehuanes de las mesas de la sierra alta;

4) los tepehuanes de los valles orientales;

5) los zacatecos y, a la vez,

6) los caxcanes semi-urbanizados de los valles orientales del sur.

Al mismo tiempo no es necesario borrar cualquier distinción sociocultural entre grupos auto-identificados como tal. Por ejemplo, es probable que los tepehuanes y zacatecos hablaban distintos idiomas (un marcador no constante, pero al menos eventual, de diferencia identitaria), por no hablar de los demás 
grupos semi-nómadas de la estepa central como los guachichiles, guamares y pames mencionados en el epilogo de su capítulo (pp. 125-128). Estos últimos probablemente eran hablantes de lenguas oto-mangues y tenían otras cosmovisiones y formas de organización social, mientras los caxcanes, zacatecos y tepehuanes eran hablantes de idiomas yuto-aztecas con relación variable a prácticas sedentarias si no ideologías urbanas. Así, al mismo tiempo que no deberían borrarse las construcciones nativas de parentesco y relaciones sociales, tampoco las alianzas coyunturales entre grupos tan diversos conllevan necesariamente la identidad cultural.

Por otro lado, el supuesto bilingüismo de los caxcanes no implica que el vernáculo necesariamente fuera tan distinto al « dialecto » del náhuatl que el cronista Tello identificó como su segundo idioma. Cabe destacar que Valiñas (1994, p. 158) no comenta sobre el idioma de los caxcanes, pero asevera con base en varios datos fonológicos que se hablaba el dialecto occidental del náhuatl en el centro de Jalisco desde la época prehispánica. Este hecho podría coincidir con la controvertida observación de Tello a principios del XVII que los caxcanes hablaban una variante « rústica » de este idioma.

Para cerrar la discusión del periodo prehispánico esbozando el punto de vista de Weigand y García (1996, p. 106) respecto a la etnicidad, Valiñas (1994) destaca las diferencias culturales al comentar que:

Parece claro que esta expansión caxcana tuvo lugar dentro de un corredor norte-sur, que realmente no era ni "chichimeca » (en el sentido de los grupos de cazadoresrecolectores-horticultores de las estepas orientales) ni « nayarita » (en el oeste) (Weigand 1985, 1992 fig. 1 y 2). Ciertamente, los grupos más hacia el oeste no compartieron las mismas lenguas que las habladas por los caxcanes y otros grupos dentro del corredor mencionado.

\section{Sin embargo, Weigand tal como Álvarez también señala continuidades:}

Hay una buena probabilidad de que los zacatecos fueran para los caxcanes el equivalente de lo que fueron los grupos de Loma San Gabriel para la cultura Chalchihuites. Los zacatecos fueron los vecinos menos desarrollados y más rurales, viviendo en simbiosis activa con los caxcanes, quienes eran sus « primos » civilizados, habitantes de las ciudades [...]. Nosotros proponemos que los zacatecos y los caxcanes representan un contimuum ecológico y sociocultural. (Weigand y Garcia 1996, p. 106)

Al contar con más datos sobre estas similitudes y diferencias, se espera que vaya a ser posible matizar las actuales polémicas.

\section{Historia COLONIAL}

Ahora pasando al periodo colonial y abordando por primera vez el tema de la resistencia, al respecto es importante reconocer un hecho fundamental sobre la 
Nueva Vizcaya colonial (que abarcó gran parte de la zona tepehuana): mientras los jesuitas impusieron sus misiones sobre los tepehuanes del norte, los franciscanos se encargaron del sur. En su capítulo « La evangelización de los tepehuanes de los valles orientales de Durango (1596-1604) », Jean-François Genotte se encarga de los jesuitas, mientras el siguiente capítulo trata de los franciscanos. De Genotte aprendemos que en 1604 había una población de 2,000 tepehuanes en torno a las misiones jesuitas de El Zape, Papasquiaro y Santa Catalina. Señala que las epidemias que acababan con gran parte de la población nativa provocaron un discurso ritual de rebelión contra los misioneros: « La situación degeneró hasta tal punto que con el fin de conjurar el mal y curar a las víctimas, los chamanes tepehuanes organizaron danzas tradicionales (mitotes) » (p. 140). Según lo que nos informa Antonio Reyes en un capítulo posterior, evidentemente la situación sigue siendo « degenerada » hoy en día, pues la tradición del mitote continúa con mucha vitalidad. Luego Genotte atribuye la resistencia a las misiones al « rechazo de manera cada vez más virulenta » de los chamanes hacia los españoles por « la inclinación que mostraba la población por los jesuitas » (p. 145).

No se cuestiona qué tan voluntaria fuera esta « inclinación », ni se explica el apoyo que también recibieron los malhechores paganos desde la misma población. Mucho menos se aborda el hecho de que, como se señala en los dos siguientes capítulos, fueron precisamente las tres antemencionadas misiones jesuitas además de Guanaceví donde había una mayor explotación de mano de obra indígena y donde la rebelión de 1616 tuvo su expresión más violenta (pp. 153, 154, 168, 171). En conjunto con la cuestión de la extracción de plusvalía, la ingerencia de especialistas rituales en la rebelión sugiere que éstos acusaron a los sacerdotes españoles de ser los brujos que habían provocado las enfermedades epidémicas de las misiones. Esto explicaría por qué los tepehuanes quemaban las casas de los muertos, y sugiere que no fueran sólo los españoles que empleaban una hermenéutica diabólica para explicar los problemas coloniales - hecho que demuestra Cramaussel en su ensayo - sino que se tratara de una cacería de brujos por parte de ambos bandos. Al mismo tiempo, el autor indica la falta de unanimidad entre los tepehuanes, o bien su aprovechamiento de la situación colonial para proseguir intereses y rivalidades propios. Esto se evidencia en el apoyo tepehuán a los españoles en la supresión de la rebelión acaxee (p. 141), lo cual demuestra que la resistencia tampoco debería verse como un atributo esencial de lo indio.

En conclusión Genotte atribuye el éxito relativo de los misioneros a cinco factores (que se toma la libertad de arreglar en orden del nivel de coacción):

1) la estética de prácticas rituales cristianas,

2) la utilización estratégica de cantos bonitos para evangelizar,

3) la exhibición de conversos tarascos y nahuas como atracción,

4) la persuasión ejercida por caciques tepehuanes convertidos,

5) la promesa de los misioneros de aliviar el hambre prevaleciente. 
A estos cinco se podría agregar la amenaza de represión violenta contra los paganos y apóstatas por medio del látigo o la espada, pues pareciera que la hegemonía siempre era de dos filos.

El capítulo de José Refugio De la Torre Curiel, « La presencia franciscana en la misiones del sur de la sierra tepehuana ", complementa el que se acaba de discutir porque examina una región más renuente a la rebelión si no colaboradora con los españoles (p. 153) ${ }^{11}$. Se enfoca en las misiones de Mezquital, Guazamota y Milpillas, aunque en cuanto al mapa étnico actual de la región es notable que el autor señala que según Arias de Saavedra (1975) la nación cristiana de tepehuanes del sur incluía a Huejuquilla, Tsenxompa [sic: Tenzompa], Mezquitic, Camotlán, y Peyotán, lugares posteriormente asociados con huicholes, coras y, en menor grado, otros grupos (p. 149 n. 11), un posible indicio de la fluidez de la territorialidad si no la plasticidad de la identidad. En sus conclusiones De la Torre nota que las secularizaciones del xviII fueron antecedentes del colapso de las misiones regulares en el siglo XIX, señalando así que con los Liberales de los 1860s sólo culminaba un proyecto de larga gestación. La iglesia reaccionó con una consolidación de provincias en 1908 y la reanudación de las labores de los franciscanos en 1934. Esto fue casi contemporáneo con la inauguración, en 1939, del programa revolucionario de educación indígena descrita en el capítulo posterior de Guerrero Durán, pero, a diferencia de las misiones franciscanas, la educación laica fue violentamente suprimida por los contra-revolucionarios cristeros de la época (p. 243).

Más allá de la cuestión de resistencia, este apartado del libro - y en particular el capítulo de Christophe Giudicelli, «Alianzas y asentamientos de guerra durante la guerra de los tepehuanes de 1616-1619»-, busca deconstruir la categorización "casi entomologista » de nación, fronteras y territorio en el discurso colonial por medio de un estudio de " intercambios, solidaridades y relaciones no previstas » (pp. 179, 164). Para Giudicelli, estos produjeron una « fluidez de identidades indígenas y una no-discontinuidad política y cultural de la sierra que contradicen directamente la compartimentación [...]» (p. 164). Giudicelli precisa además que en la rebelión de 1616,

[n]o se trata de un frente común, ni menos aún, de una engeliana guerra campesina, ni tampoco del advenimiento de una macroetnia [...]. Lo que revela la guerra, a través del juego exponencial de alianzas locales[,] es una extrema atomización política de los grupos indigenas, incluso dentro del marco de una misma nación y, al mismo tiempo, una absoluta continuidad entre estos grupos. (p. 172)

En este sentido la orientación está de acuerdo con la de Álvarez, pero aquí centrada en un caso más específico.

En primer lugar Giudicelli señala que no todos los rebeldes de 1616 eran tepehuanes y no todos los tepehuanes eran rebeldes. Luego destaca que estas categorías tampoco eran rígidas y exclusivas, cuestionando por ejemplo la iden- 
tificación automática entre lengua e identidad social. Además sugiere la existencia de lazos extensos de parentesco a través de grupos socioculturales o, en el lenguaje de la época, « naciones » (e.g., pp. 176, 177). En este sentido el modelo lévi-straussiano de la société à maison, la cual se parece más a las sociedades cognatíceas que de linaje, podría ser relevante al análisis de estas formaciones sociales fluidas en la Colonia. Varios autores han sugerido este modelo en torno a los centros ceremoniales y/o las rancherías huicholes (Neurath 2002; Liffman 2005 , respectivamente). Un aspecto clave de las sociétés à maison es que representan una forma transicional entre sociedades igualitarias y jerárquicas, lo cual se encaja con el modo tributario (o bien asiático de producción) operante a lo largo de la región desde tiempos prehispánicos. Sin embargo, luego veremos que los datos demográficos eclesiales analizados en el ensayo de Quiñones Hernández no apoyan esta hipótesis, atractiva que sea.

Ya se mencionó que Giudicelli y De la Torre señalaron la relación entre explotación de mano de obra indígena y rebelión. Sin embargo, es necesario matizar este punto porque Giudicelli también comenta que esta " presión cada vez más fuerte ejercida por la sociedad colonial sobre los indios » fue una causa necesaria pero no suficiente para explicar la rebelión tepehuana: « lo que expresa la guerra no sólo proviene del lugar ocupado por los indios en las relaciones de producción. Se deben buscar otros motivos, más directos y no reductibles a unas meras explicaciones economicistas » (p. 168). De hecho, esto es lo que ya se ha propuesto con la interpretación del papel de especialistas rituales en la rebelión, al cual Giudicelli agrega "una predicación itinerante de corte milenarista » (ibid.). Es notable en el texto colonial que cita este autor que uno de los líderes se decía dios « que traya cartas del cielo diçiendo que se abia de perder el mundo », lo cual implica también una apropiación de formas coloniales de poder (p. 169; véase van Young 1986). No obstante, para no caer en un análisis meramente discursivo, Giudicelli destaca que es necesario interpretar tales expresiones en el contexto de las redes sociales elaboradas en torno a ellos. Este enfoque impide que se descarte cualquier traslape entre « tepehuanes » como una cultura cerrada respecto a sus predecesores y vecinos.

El planteamiento de Giudicelli deriva de la perspectiva de Chantal Cramaussel, « La rebelión tepehuana de 1616. Análisis de un discurso ». Señala que hay varias causas necesarias (pero no necesariamente suficientes) de la rebelión. Éstas también podrían incluir la memoria histórica entre los tepehuanes de la reciente invasión europea de su territorio en sí, además de los factores sincrónicos a que todos aluden. En todo caso el punto clave es que el discurso así como la epistemología española sobre la rebelión fue esencialmente escatológico. Es decir que es necesario interpretar las caracterizaciones españolas de los indios en el contexto de su metafísica que centraba en el diablo como agente que provocaba la desobediencia, y no en los factores materiales que los historiadores y antropólogos modernos identificamos con las causas de la conducta humana. 
Girando desde la cuestión de la resistencia global hacia la de las alianzas locales, en «Composición demográfica de los asentamientos tepehuanes de la región sur de la Nueva Vizcaya en el siglo XVII ", Luis Carlos Quiñones Hernández señala que su propósito es medir la proporción de uniones exogámicas $v s$ endogámicas entre los tepehuanes, aspecto que resulta decisivo para comprobar el modelo de fluidez identitaria planteado por autores como Giudicelli y Álvarez, pues para ellos la evidencia de la exogamia sería fundamental. Sin embargo, Quiñones informa que

en las partidas matrimoniales de Analco, El Tunal y Santiago, pueblos de indios ubicados hacia el sur de la provincia en las inmediaciones de la capital neovizcaina, y en los demás pueblos indigenas asentados en las laderas y pequeñas mesetas de la Sierra Madre Occidental, se observa una tendencia de los contrayentes a unirse con individuos que pertenecen al mismo grupo, la que llamaremos tendencia endogámica. Por otra parte, la tendencia a contraer mupcias con individuos de otros grupos (tendencia exogámica), es apenas de 5 por ciento. [énfasis agregado]

El autor califica esta conclusión con la observación de una mayor tendencia a entablar relaciones interculturales (e interraciales) en las inmediaciones de Guadiana (la Ciudad de Durango).

¿Cómo podemos reconciliar estos datos oficiales con otras evidencias archivísticas de fluidez e interconexión grupal? Una primera respuesta tentativa sería que los curas no lograron captar todo el universo de uniones en los padrones de bodas que recibieron el sello de la iglesia católica, pues a veces se realizaron estas ceremonias con fines de herencia de propiedad mientras se cumplieron otras funciones sociales con alianzas entre distintas personas. Por ejemplo, los huicholes actuales pueden entablar varias uniones matrimoniales no sancionadas por la iglesia. Es decir, los hombres comúnmente cuentan simultáneamente con dos o más esposas (y hasta diez en el caso de ganaderos exageradamente prósperos), típicamente en diferentes rancherías que corresponden a nichos ecológicos particulares, sin reportarse a la iglesia o el registro civil.

Siguiendo con el tema de organización social indígena, Sara Ortelli, en su ensayo «Movimientos de población en misiones de tepehuanes (siglos XVII y XVIII) », complementa a Quiñones y fortalece la sugerencia de buscar más allá de los padrones oficiales. Ella señala que, a pesar de cualquier tendencia hacia la endogamia y el sedentarismo, hay « evidencias del alto grado de movilidad de los habitantes de pueblos y misiones ", además de mucha hibridez intercultural e interracial a lo largo de la región, sobre todo hacia finales de la Colonia. Un documento de la época expresa la necesidad que « todos los pueblos de naturales [...] se purguen y limpien de negros, mulatos, lobos y otras castas de gentes advenedizas, o vecinas, baldías, vagabundas [...] que [...] con el aliento y vapor de sus perversísimas costumbres contaminan las de los indios » (p. 217). Por tanto, Ortelli concluye « Así la imagen de los pueblos como asentamientos estables y 
habitados sólo por indios era una construcción, lo esperado, el ideal de organización que aparecía referido cuando se contrastaba con su dinámica real » (p. 218). Y a cambio de cualquier imagen estática, reitera lo que básicamente constituye el tema principal de los análisis históricos: « [...] los indios pacíficos y los de guerra, los agricultores y los cazadores-recolectores mantenían relaciones de intercambio y lo continuaron haciendo a pesar de los reacomodos y transformaciones que significó la presencia española » (ibid.).

Coincidiendo con las conclusiones de Ortelli, Susan M. Deeds señala en « los tepehuanes en misiones jesuitas. Cambios étnicos y culturales en los siglos xvII y XVIII » que « la diversidad de relaciones de las misiones con personas no pertenecientes a ellas fomentaba una inestabilidad inherente en las misiones » (p. 220). Al mismo tiempo, Deeds resalta la ambivalencia de las relaciones con los misioneros en el sentido que, a pesar de los muchos efectos depredadores y culturalmente destructivos de esta institución,

[h] acer un inventario somero de las varias maneras en que los indios se aprovecharon de las misiones es útil y sugerente. Las poblaciones de las misiones fueron notoriamente inestables dado que sus supuestos residentes huyeron de los pueblos con frecuencia para sustraerse a los regímenes laborales y volver a sus rancherías para cazar, recolectar y participar en fiestas rituales. Así los tepehuanes sacaron provecho de su residencia en las misiones, al adaptar su economía tradicional que implicaba migraciones temporales en terreno árido a la trashumancia del ganado introducido por lo españoles. (p. 221)

Se puede agregar otra vez que esta territorialidad variable según las estaciones del año explica parte de lo aparentemente borroso en cuanto a líneas culturales entre sierra y desierto. Y aun dentro de los constreñimientos misionales,

[1]a población indígena sin embargo mostró gran habilidad al conseguir espacios donde conservar sus costumbres y trataron con éxito de sacar provecho de su nueva situación [...] Con el tiempo también se asociaron los nativos con gente no indigenas para forjar nuevas redes sociales. (ibid.)

De hecho a veces usaron las misiones como bases de operación para una economía clandestina. De especial interés es el sincretismo no cristiano entre los diferentes grupos indígenas y africano-mexicanos: « Las prácticas autóctonas propias de los distintos grupos raciales se mezclaban en las áreas de curandería y hechicería para conjurar enemigos o amantes potenciales y frecuentemente contribuyeron a estrechar los lazos entre indios, mestizos, mulatos y españoles » (p. 225). Así insiste Deeds (igual que Genotte y Giudicelli) en la importancia de prácticas rituales en la articulación de la resistencia y los lazos de alianza entre pueblos súbditos.

Para ejemplificar su argumento Deeds cita un expediente fascinante sobre una pareja tipo Bonnie y Clyde de finales del XVII, constituida por la esclava mulata Antonia de Soto y el tepehuán Matías de Rentería, que empleaba poderes 
mágicos para posibilitar sus fugas de la autoridad y una carrera de crimen y cambios de identidad a lo largo y ancho de la mitad del territorio mexicano. Deeds concluye que:

Las fronteras porosas y fluidas de las misiones propiciaron un $\sin$ fin de transacciones, lícitas e ilícitas, que produjeron una variedad muy compleja de cambios materiales, culturales, étnicos y aun - en el caso de Antonia - de género. (p. 229)

En un abrupto cambio de tema (pues el libro no aborda tanto minas y haciendas como misiones y comunidades), Miguel Vallebueno atribuye el fenómeno señalado en el título de su ensayo, « El resurgimiento minero en la sierra de Durango durante el siglo XVIII » al incremento demográfico de la región, la consolidación de haciendas de abasto, y varias medidas administrativas. Uno podría agregar la limpieza étnica necesaria para efectuar dichos cambios, particularmente en los valles donde se establecían las haciendas (p. 232). Esta sugerencia recibe apoyo en el sentido que esta industria otra vez empezó a decaerse con el levantamiento tepehuán liderado por José María Mercado de Nayarit al final de la Colonia. Así se puede leer este capítulo a la inversa para apreciar lo prolongado de la guerra contra los tepehuanes, y cuánto afectó el desarrollo económico de Nueva Vizcaya.

Para finalizar este apartado del libro, se vuelve de las minas y haciendas a las misiones. En su breve aportación, « La iglesia de Santa María Ocotán », Clara Bargellini señala la arquitectura única de este templo cristiano que, según ella, data de principios del siglo XVIII. Su monumental torre exenta es un rasgo que en México se encuentra únicamente en Tlaxcala, Pátzcuaro, Puácaro, Cuilapan y luego Ciudad Juárez (p. 241). Arguye que es una evidencia de la influencia de los indios mercenarios tlaxcaltecas y tarascos en la colonización de la región y, sobre todo, en las misiones franciscanas. Las relaciones sociales a través del espacio que explicarían la presencia de columnas talladas en motivos naturales de flor y guías sería otra cuestión para futuras investigaciones. Este capítulo termina la sección extensa sobre historia, para dar lugar a la breve sección final sobre etnografia.

\section{ETNOGRAFÍA CONTEMPORÁNEA}

Carlos Manuel Guerrero Durán asevera al inicio de su ensayo « Análisis de los esfuerzos realizados para conservar la lengua tepehuana » que hay « dos aspectos que han propiciado la conservación de la lengua tepehuana: la educación escolar y la publicación de textos en tepehuán » aunque admite al final que "las estrategias de atención han sido en general insuficientes e ineficaces » (pp. 243, 249). Este planteamiento no toma en cuenta los reclamos de líderes indígenas que la llamada educación bilingüe promovida por la Secretaría de Educación Pública (SEP) durante muchos años más bien provocaba el deterioro 
en el uso de lenguas indígenas debido a su tendencia de alfabetizar primero, si no exclusivamente, en español y promover valores asimilacionistas. Así resulta un poco paradójico leer que « en 1979 se lanzó un programa de capacitación para treinta jóvenes indígenas que apoyarían las tareas de castellanización, por medio de métodos bilingües y biculturales, afirmando así sus valores, su lengua y sus tradiciones » (p. 245). De hecho, el autor señala que no fue hasta 1994 que las autoridades empezaron a capacitar a los maestros a que enseñaran el o'dam escrito. Los primeros libros de texto en este idioma finalmente salieron el año siguiente, y un pequeño diccionario bilingüe de 1,700 entradas en 1997 (p. 247). No queda claro qué tanto esto haya resultado en la alfabetización en o'dam o el logro de otros proyectos de rescate lingüístico-cultural. Por otro lado, el autor no alude a los propios mecanismos de resistencia a la hegemonía del idioma de los mestizos que los tepehuanes han demostrado a lo largo de siglos. Pues la conservación de su propio idioma o'dam como símbolo y medio de la lucha por la autonomía identitaria ha sido un aspecto clave de dicha resistencia.

Sin embargo el autor provee una valiosa cronología de los esfuerzos educativos en la región desde el antemencionado intento fallido de la época cardenista. Éste fue seguido en los años 1950s por la llegada del Instituto Lingüístico de Verano, notablemente Thomas Willett $(1991 ; 2001)$, cuyo diccionario bilingüe salió en 1978. A partir de 1963, casi 25 años después del primer intento, la SEP empieza a desarrollar escuelas entre los tepehuanes. Esto fue contemporáneo con semejantes esfuerzos educativos y resoluciones de la tenencia de la tierra entre los huicholes y coras, precondiciones para el desarrollo regional contemplado en el Plan HUICOT. Ya para 1992, en vísperas de los primeros textos realmente bilingües, la zona tepehuana contó con 57 centros preescolares con 718 niños, 126 primarias para arriba de 4,000 alumnos y 23 centros del INEA dirigidos a 575 padres de familia.

Ahora enfocando en los procesos simbólicos internos de las comunidades - perspectiva que se comparte con los dos capítulos que lo siguen - J. Antonio Reyes, en "Sistema de cargos entre los tepehuanes del sur. El caso de los danzantes y los jinetes ancestros portadores de lluvia », presenta evidencia de la mesoamericanización de los tepehuanes del sur en tiempos históricos (véase Reyes 2004; 2007). A diferencia del sur de México, la instauración de sistemas de cargos en muchas de estas comunidades (aun los que eran centros de administración colonial desde fechas relativamente tempranas, como Ocotán) no anteceden finales del siglo XVIII (véase Coyle 2001). Por otro lado, la falta de simbolismo direccional elaborado, muy desarrollado entre los vecinos coras y huicholes y en la tradición arqueológica de la región, indica que sigue habiendo diferencias culturales profundas entre estos grupos colindantes.

Denis Lemaistre, en «Similitudes y contrastes entre los sistemas festivos tepehuano del sur y huichol » también señala las coincidencias y distinciones entre pueblos colindantes. Destaca en particular que « $\mathrm{Al}$ parecer, no existe en el 
caso tepehuano una fuerte dicotomía entre rancherías y centro políticoceremonial ", lo cual sí existe entre coras y huicholes. Esta jerarquización del espacio parece ser un aspecto que dejaba de reproducirse en esta área después de los chalchihuiteños ${ }^{12}$.

El ensayo final, «Los tepehuanos en el mundo mexicanero de San Pedro Jícaras, Durango » de Neyra Alvarado Solís, trata de una comunidad bicultural, enfocando en « aspectos rituales en donde se manifiesta el lugar que ocupan los tepehuanos en la concepción mexicanera » (p. 269). Este enfoque complementa el de Cramaussel y otros historiadores de la región puesto que toma en cuenta la representación de pueblos indios a través de las categorías discursivas o la imaginería de un grupo nativo sobre otro. Dado que Alvarado señala « matrimonios entre ambos grupos y bilingüismo (trilingüismo con el español) » (p. 269), tal vez no se trate tanto de "pueblos", "culturas » o aun " concepciones » distintos sino de tropos en un ambiente híbrido. Este análisis indica mecanismos que facilitan la articulación de grupos, la cual los trabajos de otros autores plantean como característica fundamental de toda la región desde tiempos prehispánicos.

Se puede bosquejar las relaciones estructurales entre los mexicaneros (el grupo autóctono de San Pedro, que tiene preeminencia ritual en el lugar) y tepehuanes (grupo advenedizo con mayor poder regional) así:

\begin{tabular}{|c|c|c|c|c|c|c|}
\hline & sur: & chamanismo: & femenino: & oscuridad: & lluvia: & maíz \\
\hline & nte: & cargo civil: & masculino: & sol: & sequedad: & dinero \\
\hline
\end{tabular}

En este sistema los tepehuanes mediatizan los sistemas regionales de poder y con ello el mundo mestizo. Es un modelo de articulación que podría elucidar otros datos presentados a lo largo del volumen y en otra literatura sobre la región. Así se plantea un punto de enlace para futuras discusiones entre antropólogos, historiadores, y arqueólogos.

\section{CONCLusiones}

Las evidencias etnohistóricas y etnográficas sugieren mecanismos por los cuales se podían haber construido los contimum o bien alianzas eventuales entre pueblos de la región tepehuana. Se destacan prácticas chamánicas y lo que Johannes Neurath denomina el complejo mitote - la socialización y el intercambio ritual - que tanto peso tuvo en la rebelión tepehuana de 1616 para articular una ideología de resistencia milenarista contra los españoles. Aparte, las alianzas matrimoniales parecen haber sido otro mecanismo importante de vincular poblaciones a través de líneas culturales. Por tanto, a pesar de los riesgos de hacer analogías etnográficas desde el siglo XVII (e inclusive desde el XXI) hacia el XIII, lo que se ha documentado en cuanto a sociedades bilaterales, cognaticias o à maison 
en la región puede haber sido relevante antes de la Colonia (Carsten y HughJones 1995). Pues las redes construidas por la adscripción fluida de allegados a rancherías cuyas identidades giran en torno a procesos ceremoniales centrados en el patio ceremonial daría lugar a lo que Giudicelli ha caracterizado como « una extrema atomización política de los grupos indígenas, incluso dentro del marco de una misma nación, y al mismo tiempo, una absoluta continuidad entre estos grupos ».

Como aspecto de esta atomización (o bien particularidad) de todas las agrupaciones indígenas de la región, no se puede esencializar a los « tepehuanes » como tal, sino verlos todos en relaciones de aculturación con sus vecinos inmediatos. Por tanto, la relativa mesoamericanización de los tepehuanes del sur colindantes con los huicholes y coras y la relativa tarahumarización de los tepehuanes de Ocotán y San Pablo en el norte. Si esta tendencia de borrar las distinciones culturales mediante la apropiación de prácticas de vecinos también se manifestara en la época prehispánica aún está por verse, aunque Hers y Berrojalbiz insisten que había poco traslape entre dichos grupos en la región de Loma San Gabriel. La relación entre tepehuanes y los que habitaban la sierra alta hasta mediados de la época colonial fue otro asunto en el que los tributos se dirigían más hacia los allegados que los mesoamericanos más asentados (Berrojalbiz, communicación personal). Sean como sean las continuidades entre grupos, como el mismo Giudicelli reconoce, al relativizar y deconstruir categorías que a fin de cuentas servían de herramientas de administración colonial, no deberíamos de borrar las diferencias duraderas que los mismos sujetos indígenas constituyeron entre comunidades y otras unidades socioculturales. Así, por ejemplo, la territorialidad variable de los pueblos de la Sierra Madre Occidental según las estaciones del año explica parte de lo aparentemente borroso en cuanto a líneas culturales entre sierra y desierto. Al mismo tiempo esta territorialidad tampoco disuelve lazos primordiales con los centros ceremoniales, cuyas actividades siguen definiendo la organización social e identidad cultural hasta la fecha. *

* Manuscrit reçu en janvier 2009, accepté pour publication en octobre 2009.

\section{NOTAS}

1. Se agradece a Chantal Cramaussel por su invitación a discutir el libro que subyace este ensayo en el Seminario del Norte, Centro de Estudios Históricos, del Colegio de Michoacán, a Dominique Raby y Andrew Roth por sus valiosas observaciones sobre el texto en general y a Raby por su ayuda con los etnónimos en náhuatl en particular.

2. Los arqueólogos son Marie-Areti Hers, Yoshiyuki Tsukada, José Luis Punzo Díaz y Fernando Berrojalbiz.

3. Los historiadores son Salvador Álvarez, Jean-François Genotte, José Refugio De la Torre Curiel, Christophe Giudicelli, Chantal Cramaussel, Luis Carlos Quiñones Hernández, Sara Ortelli, Susan Deeds, Miguel Vallebueno y Clara Bargellini. 
4. Los etnógrafos son Carlos Manuel Guerrero Durán, Antonio Reyes, Denis Lemaistre y Neyra Alvarado.

5. Como ejemplo del énfasis sobre el eje norte-sur, Weigand y García (1996, pp. 85-86) se refieren a un continumm Chalchihuites-Malpaso-Juchipila-Loma San Gabriel, aunque esta última categoría todavia falta matices en el espacio y tiempo (William Merrill comunicación personal).

6. Cabe agregar que en la actualidad los huicholes - pueblo que habita la zona inmediatamente al sur de los tepehuanes - siguen accediendo con fines tanto ceremoniales como económicos a todos los cinco nichos de manera estacional.

7. Uno podria especular si esta superimposición o sucesión de poblaciones yuxtapuestas correspondería a la tradición histórica huichola de los hewixi, gigantes cuya torpeza condujo a su extinción, pero cuyas casas grandes luego llegaron a ser los primeros centros ceremoniales de los huicholes.

8. Agrega Valiñas (2000, p. 202) que, por las diferencias fonológicas, la separación entre tepehuán y pima probablemente fue temprana. Aunque esto no nos ocupe tanto en el caso del tepehuán norte y sur, sugiere al menos que tampoco se desprendieron todos los idiomas de la subfamilia desde el mismo momento tardío.

9. Sin embargo en un ensayo posterior, Hill (2001) plantea la región de los coras y huicholes en Nayarit y Jalisco como el punto de origen de toda la familia yuto-azteca, basándose en la hipótesis determinista que el gran alcance geográfico de la familia sólo puede explicarse a base de su superioridad tecnológica. Según ella, eran los portadores de la agricultura del maíz hacia el norte en vez de un pueblo del norte que encontró la agricultura uno o dos milenios después de diferenciarse en tierras norteñas. Este movimiento (que además empezó muy tarde, en torno a $1000 \mathrm{aC}$ ) se debe a que las familias oto-mangue, purhépecha y mixe-zoque, cuyos hablantes eran colindantes en el centro de México, ya habian dominado la agricultura en siglos anteriores. Por el poder de sus sistemas productivos, no permitian que los yuto-aztecas crecieran en ninguna dirección sino hacia el norte. Aquí se nota la similitud con Hers en el sentido que el cambio cultural se identifica con el movimiento concreto de poblaciones. Hill (2001, p. 926 ) se centra en la presencia de cognados en todas las lenguas proto-yutoaztecas que supuestamente se refieren a la agricultura de maíz. Sin embargo, ella reconoce que las referencias al maíz podrian representar una redefinición posterior de otros significados etnobotánicos si no fuera por la parsimonia de ver los paralelismos como resultado de una sola causa anterior a la división de las lenguas integrantes de la familia. La cuestión entonces radica en la probabilidad de la evolución paralela de referencia al maíz en lenguas ya separadas a base de las mismas palabras preexistentes en cada idioma.

10. Álvarez ha intentado derivar etimologías de los etnónimos coloniales, los cuales admite que nos informan más sobre los españoles y sus mercenarios hablantes del náhuatl que la gente a las que se los ponian (p. 114). El diccionario del náhuatl clásico de Simeón rinde las siguientes raíces posibles: Tepehuán: te $=$ objeto humano + pewa $=$ conquistar + -ni=habitual $=$ " conquistadores $»$ o tepetl $=$ cerro + -wan=dueño = « dueño de cerro » (en vez de « antropófago » como plantea Álvarez, pues éste es más bien un eptiteto). Se opone a Caxcán: kaxitl=escudilla o plato + -kan = «lugar (del o en forma de) plato o escudilla $"$.

11. La interpretación de Riley et al. $(1959 ; 1963)$ es que los tepehuanes de esta región se retiraron a las partes más inaccesibles de la Sierra Madre Occidental para evitar los misioneros y así defender su cultura. El análisis de este autor (1959) sobre el movimiento nativista tepehuán de los años 1950s podría servir como modelo para interpretar algunos datos de los levantamientos coloniales.

12. Las investigaciones arqueológicas de Zavala (2007) comprueban el uso de simbolismo direccional para ordenar construcciones ceremoniales chalchihuiteñas. 


\section{REFERENCIAS CITADAS}

Arias de SaAvedra Antonio

1975 "Franciscan report on the Indians of Nayarit [1673] », por Kieran McCarty y Dan S. Matson, Ethnohistory, 22 (3), pp. 193-222.

CARsten Janet y Stephen Hugh-Jones (eds)

1995 About the house: Lévi-Strauss and beyond, Cambridge University Press, Cambridge.

Coyle Philip E

2001 Flowers and ash: Náyari history, politics and violence, University of Arizona Press, Tucson.

Cramaussel Chantal y Sara Ortelli

2006 La Sierra Tepehuana. Asentamientos y movimientos de población, El Colegio de Michoacán/Universidad Juárez del Estado de Durango, Zamora.

Hers Marie-Areti y José Luis Mirafuente (eds)

2000 Nómadas y sedentarios en el norte de México. Homenaje a Beatriz Braniff, Universidad Nacional Autónoma de México, México.

Hill Jane H

2001 «Proto-Uto-Aztecan: a community of cultivators in central Mexico?», American Anthropologist, 103 (4), pp. 913-934.

LEACH Edmund R.

1964 Political systems of highland Burma: a study of Kachin social structures, London School of Economics and Political Science/University of London/G. Bell, London [1954].

LIFFMAN Paul

2005 «Raíces y fuegos: estructuras cosmológicas y procesos históricos y de migración interna en la territorialidad wixarika », Relaciones, 26 (101), « El Gran Nayar, patrones de cambio e intercambio », pp. 53-79.

Mandelbaum David

1949 " Time perspective in aboriginal American culture: a study in method », in David Mandelbaum (ed.), Selected writings of Edward Sapir, University of California Press, Berkeley, pp. 389-462.

MiLLeR Wick

1983 «Uto-Aztecan languages », in Alfonso Ortiz (ed.), Southwest. Handbook of North American Indians, 10, Smithsonian Institution, Washington, pp. 113-124.

1984 "The classification of the Uto-Aztecan languages based on lexical evidence ", International Journal of American Linguistics, 50 (1), pp. 1-24.

NEURATH Johannes

2002 Las fiestas de la casa grande: procesos rituales, cosmovisión y estructura social en una commidad huichola, INAH, México/Universidad de Guadalajara, Guadalajara. 


\section{Reyes VALdez Jorge Antonio}

2004 Pimas, pápagos y tepehuanes. Relaciones lengua-cultura entre los pueblos tepimanos del noroeste de México y el suroeste de los Estados Unidos, tesis de maestría en antropología, FFyL-UNAM, México.

2007 Los que están benditos: el mitote comumal de los tepehuanes de Santa María de Ocotán, Durango, INAH, México.

RiLey Carroll L. y John HoBgood

1959 "A recent nativistic movement among the Southern Tepehuan Indians ", Southwestern Journal of Anthropology, 15 (4), pp. 355-360.

RiLey Carroll L. y Howard D. WINTERS

1963 " The prehistoric Tepehuan of Northern Mexico », Southwestern Journal of Anthropology, 19 (2), pp. 177-185.

Shaul David Leedom y Jane H. Hill

1998 "Tepimans, Yumans, and other Hohokam", American Antiquity, 63 (3), pp. 375-396.

VALIÑas COALLA Leopoldo

1994 "Transiciones lingüísticas mayores en Occidente ", in Ricardo Ávila Palafox (ed.), Transformaciones mayores en el Occidente de México, Universidad de Guadalajara, Guadalajara, pp. 127-166.

2000 «Lo que la lingüística yutoazteca podría aportar en la reconstrucción histórica del norte de México ", in Marie-Areti Hers y José Luis Mirafuente (eds), Nómadas y sedentarios en el norte de México. Homenaje a Beatriz Braniff, Universidad Nacional Autónoma de México, México pp. 175-205.

Valiñas Coalla Leopoldo y Mario Cortina Borja

1987 «Contribución a la reconstrucción histórica a partir de métodos estadísticos en datos léxicos: el caso de las lenguas sonorenses ", Memoria del XII Simposio de Historia y Antropologia de Sonora, Universidad de Sonora, Instituto de Investigaciones Históricas, Hermosillo, vol, 1, pp. 387-411.

Weigand Phil C.

1985 «Evidence for complex societies during the western Mesoamerican Classic period », in Michael S. Foster y Phil C. Weigand (eds), The archaeology of west and northwest Mesoamerica, Westview Press, Boulder, pp. 47-91.

1992 Ensayos sobre el Gran Nayar: entre coras, huicholes y tepehuanes, CEMCA/INI, México/El Colegio de Michoacán/Zamora.

Weigand Phil C. y Acelia García de Weigand

1996 Tenamaxtli y Guaxicar: las raices profundas de la rebelión de Nueva Galicia, traducción de Eduardo Williams, El Colegio de Michoacán, Zamora/Secretaría de Cultura de Jalisco, Guadalajara.

WILLETT Thomas L.

1991 Reference grammar of southeastern Tepehuan, Summer Institute of Linguistics, Dallas. 
2001 "Resumen de los estudios lingüísticos del tepehuan: norte y sur », in José Luis Moctezuma Zamarrón y Jane H. Hill (eds), Avances y balances de lenguas yutoaztecas. Homenaje a Wick $R$. Miller, Instituto Nacional de Antropología y Historia, México.

Young Eric Van

1986 "Millenium on the northern marches: the mad messiah of Durango and popular rebellion in Mexico, 1800-1805 », Comparative Studies in Society and History, 28 (3), pp. 385-413.

Zavala Bridget M.

2007 «Bajikam ausentes, bajikam presentes: la trascendencia de la muerte vista por la arqueología de Durango ", Ponencia presentada en el simposio Cuerpo y muerte en el noroeste de México, XXVIII Mesa Redonda de la Sociedad Mexicana de Antropología, 8 agosto, México. 